\title{
Reduced Electromotility of Outer Hair Cells Associated with Connexin-Related Forms of Deafness: An In silico Study of a Cochlear Network Mechanism
}

\author{
Pavel Mistrík $^{1,2}$ and Jonathan F. Ashmore ${ }^{1,2}$ \\ ${ }^{1}$ UCL Ear Institute, 332 Gray's Inn Road, London, WC1E 6BT, UK \\ ${ }^{2}$ Department of Neuroscience, Physiology and Pharmacology, UCL, Gower Street, London, WC1E6BT, UK
}

Received: 16 December 2009; Accepted: 23 June 2010; Online publication: 16 July 2010

\begin{abstract}
Mutations in the GJB2 gene encoding for the connexin 26 (Cx26) protein are the most common source of nonsyndromic forms of deafness. Cx26 is a building block of gap junctions (GJs) which establish electrical connectivity in distinct cochlear compartments by allowing intercellular ionic (and metabolic) exchange. Animal models of the Cx26 deficiency in the organ of Corti seem to suggest that the hearing loss and the degeneration of outer hair cells (OHCs) and inner hair cells is due to failed $\mathrm{K}^{+}$and metabolite homeostasis. However, OHCs can develop normally in some mutants, suggesting that the hair cells death is not the universal mechanism. In search for alternatives, we have developed an in silico large scale three-dimensional model of electrical current flow in the cochlea in the small signal, linearised, regime. The effect of mutations was analysed by varying the magnitude of resistive components representing the GJ network in the organ of Corti. The simulations indeed show that reduced GJ conductivity increases the attenuation of the $\mathrm{OHC}$ transmembrane potential at frequencies above $5 \mathrm{kHz}$ from $6.1 \mathrm{~dB} /$ decade in the wild-type to $14.2 \mathrm{~dB} /$ decade. As a consequence of increased GJ electrical filtering, the $\mathrm{OHC}$ transmembrane potential is reduced by up to $35 \mathrm{~dB}$ at frequencies $>10 \mathrm{kHz}$. OHC electromotility, driven by this potential, is crucial for sound amplification, cochlear sensitivity and frequency selectivity. Therefore, we conclude that
\end{abstract}

Correspondence to: Jonathan F. Ashmore - Department of Neuroscience, Physiology and Pharmacology - UCL - Gower Street, London, WC1E6BT, UK. Telephone: +44-20-77692141; email: j.ashmore@ucl. ac.uk reduced $\mathrm{OHC}$ electromotility may represent an additional mechanism underlying deafness in the presence of Cx26 mutations and may explain lowered $\mathrm{OHC}$ functionality in particular reported Cx26 mutants.

Keywords: cochlea, gap junction, outer hair cell, modelling, cochlear mechanics

\section{INTRODUCTION}

Deafness exists in a variety of inherited nonsyndromic forms, with more than 70 loci identified so far (Petit 2006). Mutations in a single gene, the gap junction beta 2 (GJB2) gene, account for nearly $50 \%$ of cases. The GJB2 gene encodes for the protein connexin $26(\mathrm{Cx} 26)$, which together with other connexins such as $\mathrm{Cx} 30$, forms the gap junctions between non-sensory cells in the cochlea (for review, see Nickel and Forge 2008; Rabionet et al. 2000). The most common GJB2 mutations are single nucleotide deletions and frame shifts (such as $35 \mathrm{delG}, 167 \mathrm{delT}$, and $235 \mathrm{delC}$ ). These are well documented as leading to deafness in human populations. Missense mutations such as M34T or R75W have a dominant negative effect on hearing (Rabionet et al. 2000) and functional analysis of such mutations have identified reduced ionic conductivity of the gap junction (GJ) as the associated defect (Bicego et al. 2006; Bruzzone et al. 2003). It has also been proposed that mutations such as V84L, with reduced permeability to metabolites such as $\mathrm{IP}_{3}$ (Beltramello et al. 2005) may exert their effect by interfering with the development and maintenance of the organ of Corti. 
A

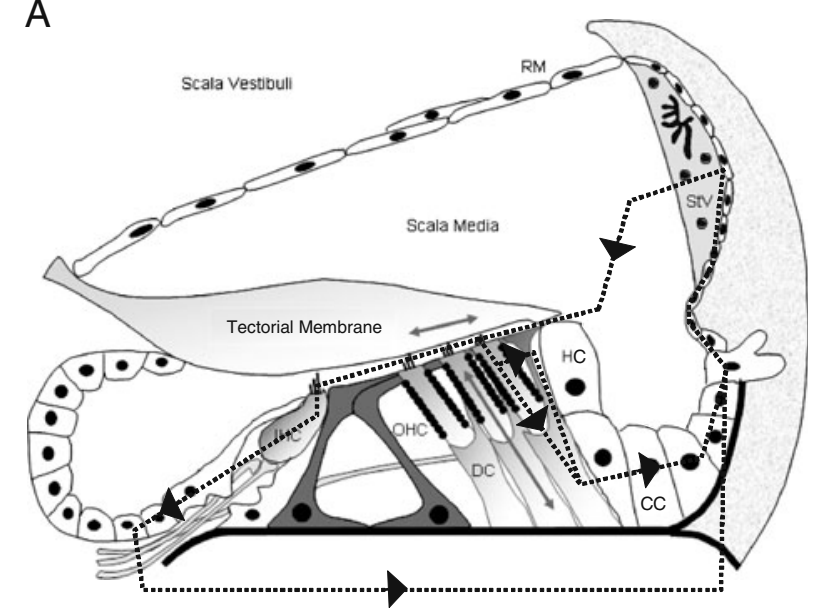

B

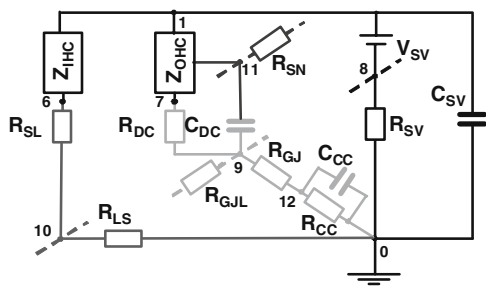

D

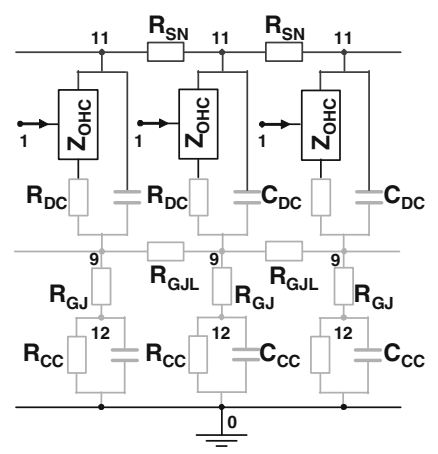

C

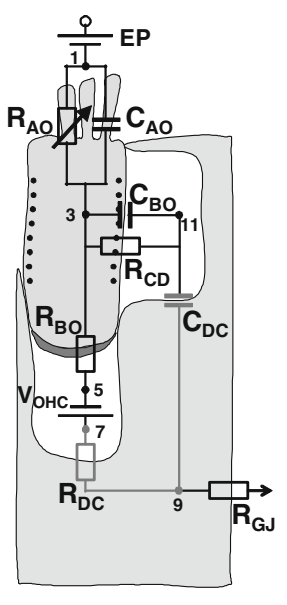

FIG. 1. The three-dimensional model of current flow in the cochlea. A Schematic representation of radial current flow between different cochlear compartments in a single cross-section with stria vascularis (StV), inner/outer hair cells (IHC/OHC), Deiters' (DC), Hensen (HC), Claudius (CC) cells and Reissner's membrane (RM). B An equivalent electrical circuit of a cochlear cross-section, $Z_{\mathrm{IHC}}$ and $\mathrm{Z}_{\mathrm{OHC}}$, the effective $\mathrm{IHC}$ and $\mathrm{OHC}$ impedances, respectively. The circuit implants the detailed current flow around the $\mathrm{OHC}$ seen in $(\mathbf{C})$. $\mathrm{R}_{\mathrm{DC}}$ and $\mathrm{C}_{\mathrm{DC}}$, effective resistor and capacitor of Deiters' cells membrane; $R_{H C}$ and $\mathrm{C}_{\mathrm{CC}}$ for Claudius cells; $\mathrm{V}_{\mathrm{SV}}, \mathrm{R}_{\mathrm{SV}}$ and $\mathrm{C}_{\mathrm{SV}}$, the effective battery, resistance and capacitance of stria vascularis; $R_{S L}$ and $R_{\mathrm{LS}}$, resistors of spiral limbus; $R_{\mathrm{G}}$, radial GJ connection between Deiters'and Claudius cells. Nodes 8, 9 and 10 are coupled between adjacent cross-sections and represent longitudinal intercellular GJ connections in $\mathrm{StV}$, organ of Corti and spiral limbus. Nodes 11 in adjacent sections are connected by the resistor $R_{\mathrm{SN}}$ representing the space of Nuel (extracellular space surrounding OHCs). C Electrical coupling between an outer hair cell and a supporting cell (the $\mathrm{OHC}$ impedance in detail). $R_{A O}, C_{A O}$ resistance and capacitance of the OHC apical membrane $\left(R_{A O}\right.$ is modulated by sound input); $R_{B O}, C_{B O}$ resistance and capacitance of $\mathrm{OHC}$ basolateral membrane; $V_{\mathrm{OHC}}$ the $\mathrm{OHC}$ electrochemical battery, EP endocochlear potential. The IHC impedance is treated similarly, but $\mathrm{R}_{\mathrm{BI}}$ and $\mathrm{C}_{\mathrm{BI}}$, the resistor and capacitor representing IHC basolateral membrane, are in parallel. Nodes 3 and 5 of IHC correspond to 2 and 4 of $\mathrm{OHC}$ (Mistrik et al. 2009). See Table 1 for values. D View of the circuit along the tonotopic axis at the level of OHCs and showing longitudinal current flow extracellularly through the space of Nuel (node 11 and $R_{\mathrm{SN}}$ ) and intercellularly through organ of Corti (node $9, R_{\mathrm{GJL}}$ ).

Mutations in GJs can lead to the apoptosis of hair cells. This has been observed in an animal model with a cochlea-specific GJB2 ablation (Cohen-Salmon et al. 2002). The observation is compatible with GJs serving to buffer extracellular $\mathrm{K}^{+}$by supporting cells, as occurs in astrocytes in the central nervous system (Kikuchi et al. 2000; Santos-Sacchi 1985). Nevertheless, cell degeneration is not inevitable, for it has been shown in an animal model expressing the human dominant-negative Cx26 mutation $\mathrm{R} 75 \mathrm{~W}$ that there may be significant anatomical deformations of the organ of Corti (Kudo et al. 2003), but that the outer hair cells (OHCs) develop normally (Minekawa et al. 2009).

Audiological examination of patients carrying GJB2 mutations exhibit reduced or missing distortion product oto-acoustic emissions (DPOAEs; Engel-Yeger et al. 2002; Engel-Yeger et al. 2003; Medica et al. 2005; Morell et al. 1998) although not in every case (Cheng et al. 2005; Santarelli et al. 2008). As reduction of the DPOAE is a sign of non-functional OHCs, such finding suggests that the underlying pathology in this case might be reduced OHC electromotility, essential for the active amplification of sound as shown by animal experiments where the 'motor' protein has been deleted (Liberman et al. 2002) or reduced (Cheatham et al. 2009).

Gap junctions constitute two major systems of intercellular communication in the cochlea: the epithelial cell gap junction system coupling supporting cells in the organ of Corti and the connective tissue gap junction system connecting the type 2 fibrocytes in the spiral ligament with basal and intermediate cells in the stria vascularis (Nickel and Forge 2008; Zhao et al. 2006). It is widely held that the passage of ions, mainly $\mathrm{K}^{+}$from scala media, generates electrical currents in the cochlear partition upon the activation by sound of the mechanotransducer (MET) channels in hair cells (Figure 1A). This ion flow constitutes an electrical current pathway in the cochlea. 
We have recently developed a large-scale in silico model to describe current flow in the cochlea (Mistrik et al. 2009). Such large-scale 3D models have been developed previously to study cochlear potentials (Strelioff 1973) and in vivo cochlear stimulation (Suesserman and Spelman 1993). The model used here differs in several important aspects: (1) it is finer grained (the cochlea is divided into 300 cross-sections instead of 90 or 51 sections as previously used); (2) it uses a more accurate algorithm for the calculation of basilar membrane (BM) displacements (Mammano and Nobili 1993); and (3) the organisation of the equivalent electrical circuit reflects the advances in characterization of the molecular components of the cochlea and their electrical properties.

Such a model represents a prototype of an in silico diagnostic tool to asses the effect on system cochlear potentials of constituent molecular mutations. Previously, we used the model to analyse the role of lateral current spread through GJs in controlling extracellular field potentials and electrical filtering in the cochlear network (Mistrik and Ashmore 2009, Mistrik et al. 2009). The essential demonstration in such a model is that the extracellular fields around the $\mathrm{OHCs}$ can drive the cell's electromotility largely independently of the cell's time constant, and that these fields are modulated by current spreading through the gap junction systems in the cochlea. Such simulations show that the GJ systems are critical for keeping the anticipated frequencydependent roll-off of the $\mathrm{OHC}$ transmembrane potential relatively small (6 dB/decade). For comparison, the potential of an isolated cell, outside a coupled network, would be reduced by $21 \mathrm{~dB} /$ decade or $6 \mathrm{~dB} /$ octave once above its corner frequency.

In this paper, we describe the method of implementing in the model the effects of different types of $\mathrm{Cx}$ mutations and the consequences for cochlear tuning and amplification. The simulations suggest that $\mathrm{Cx} 26$ mutations could increase the attenuation of the $\mathrm{OHC}$ transmembrane potential from $6 \mathrm{~dB} /$ decade to $14.2 \mathrm{~dB} /$ decade and reduce the electromotile forces by up to $35 \mathrm{~dB}$ at frequencies greater than $10 \mathrm{kHz}$. Such a decrease could nearly completely eliminate the $40 \mathrm{~dB}$ gain due to cochlear amplification associated with normal hearing. Such a mechanism might explain the impaired DPOAEs in spite of normal OHC non-linear capacitance in the R75W mutant mouse (Minekawa et al. 2009) and the absence of DPOAEs in subjects carrying the $35 \mathrm{delG}$ (Engel-Yeger et al. 2002) or 167delT (Morell et al. 1998) mutations.

\section{METHODS}

\section{An equivalent electrical circuit of the cochlea}

The elementary circuit describing the radial current flow in a single cross-section is shown in Figure 1B. It is derived from a two-dimensional equivalent electrical model of the organ of Corti (Dallos 1984). Here, effective IHCs and OHCs are treated separately and assigned impedances $\mathrm{Z}_{\mathrm{IHC}}$ and $\mathrm{Z}_{\mathrm{OHC}}$, respectively (Jagger and Forge 2006). The three rows of OHCs (and Deiters' cells) were simulated as one row and the membrane parameters adjusted accordingly. The $\mathrm{OHC}$ is connected to a Deiters' cell through a pathway expected to pass $\mathrm{K}^{+}$ions during sound stimulation (Boettger et al. 2002; Johnstone et al. 1989; Santos-Sacchi 1985). The circuitry between an $\mathrm{OHC}$ and a supporting cell is shown in detail in Figure 1C. In contrast to previous models (Dallos 1984; Mountain and Cody 1999; O'Beirne and Patuzzi 2007; Ospeck et al. 2003), the resistors and capacitor describing the OHC baso-lateral membrane are distributed. This is to accommodate the observed spatial separation of $\mathrm{K}^{+}$conductances $\left(\mathrm{R}_{\mathrm{BO}}\right)$ in the basal pole buried in the interface with a Deiters' cell (node 7) and the lateral membrane with prestin $\left(\mathrm{C}_{\mathrm{BO}}\right)$ exposed to perilymph (node 11) of the space of Nuel (Boettger et al. 2002; Winter et al. 2007; Yu et al. 2006). A resistive pathway between the space of Nuel (node 11) and the perilymph (node 0 ) suggested by in vivo measurements of cochlear receptor potentials (Dallos et al. 1982) is facilitated in the model by current flowing through the capacitance divider $\mathrm{C}_{\mathrm{BO}}-\mathrm{C}_{\mathrm{DC}}$ at the acoustic frequencies explored here. Simulations with an additional resistive element directly connecting these two nodes did not affect the gain functions calculated below and were not considered further. The additive effect of the $\mathrm{OHC}$ nonlinear capacitance (Spector et al. 2003) was included in the $\mathrm{C}_{\mathrm{BO}}$ value and its voltage dependence was not considered in the model as only small signals are being considered. To keep within reasonable computational times without resorting to high performance computing clusters, the complex cellular structure of stria vascularis, important for the generation of the endocochlear potential (Nin et al. 2008; Quraishi and Raphael 2008), was represented only as a single compartment and its electrical properties characterised by an effective resistor and capacitor $\left(\mathrm{R}_{\mathrm{SV}}\right.$ and $\mathrm{C}_{\mathrm{SV}}$, respectively). A battery, $\mathrm{V}_{\mathrm{SV}}$, represents the mechanism for generating endocochlear potential, essentially at a constant value in this simulation.

The radial GJ conductance between supporting cells in the organ of Corti was implemented explicitly by the resistor $R_{\mathrm{GJ}}$ connecting "uncoupled" Deiters' $\left(\mathrm{R}_{\mathrm{DC}}\right.$ and $\mathrm{C}_{\mathrm{DC}}$ ) and cells lining the basilar membrane. These cells consist of Hensen's cells, Claudius cells and Boettchers' cells (at cochlear basal turns). The circuit connections were simplified to a single-lumped element consisting of a parallel $\mathrm{R}_{\mathrm{CC}}$ and $\mathrm{C}_{\mathrm{CC}}$ as done previously (Lagostena et al. 2001; Santos-Sacchi 1991; Santos-Sacchi and Dallos 1983). The main effect of this pathway is to allow a pathway to perilymph at high frequencies. The use of a single resistance/capacitor for theses sets of cells in each of 300 cross-sections ensured that the computational load was kept at reasonable levels although the intracellular potential of supporting cells was not defined in the circuit.

The longitudinal GJ conductance between adjacent crosssections was implemented by three resistive connections by 
$R_{\mathrm{GJL}}$ (see Figure 1D). The connection through the node 9 represents intercellular coupling in the organ of Corti; through the node 8 , the coupling in stria vascularis and through the node 10 in the spiral limbus. An additional longitudinal coupling by the resistance $R_{\mathrm{SN}}$ through the node 11 represents a low-impedance pathway at all frequencies through the extracellular space surrounding OHCs in the organ of Corti (Mountain and Cody 1999).

The acoustic stimulus was implemented by modulation of resistances $\mathrm{R}_{\mathrm{AO}}$ and $\mathrm{R}_{\mathrm{AI}}$, which represent the MET channels in apical stereocilial membrane of the $\mathrm{OHC}$ and IHC respectively (Figure $1 \mathrm{C}$ shows the case of $\mathrm{R}_{\mathrm{AO}}$ ). The MET conductances were modulated around their steady state values in proportion to the basilar membrane displacement computed by a model of BM mechanics (Mammano and Nobili 1993). This model gives realistic $\mathrm{BM}$ tuning, with the result that $\mathrm{R}_{\mathrm{AI}}$ and $\mathrm{R}_{\mathrm{AO}}$ were effectively modulated in $10-20 \%$ of the 300 cross-sections (see below). The critical OHC receptor potential, generated by such sound stimuli, is the voltage difference between nodes 3 and 11 (Figure 1C). This is the OHC lateral transmembrane potential which drives conformational changes in the prestin molecule.

The values of circuit parameters are summarised in Table 1. For both hair cells and supporting cells, these represent effective values at each of 300 cross-sections derived from single cells characteristics (multiple data sources) by appropriate scaling: taking the length of the guinea pig cochlea as $18 \mathrm{~mm}$ and the distance between the hair cells rows as $10 \mu \mathrm{m}$, each cross-section contains six IHCs, 18 OHCs and 18 Deiters', Hensen, Claudius and Boettcher's cells (each of them in parallel). Batteries $\mathrm{V}_{\mathrm{IHC}}$ and $\mathrm{V}_{\mathrm{OHC}}$ represent $\mathrm{K}^{+}$electrochemical gradient for IHC and $\mathrm{OHC}$, respectively (Ospeck et al. 2003). The effective resistance values for spiral limbus and stria vascularis were chosen to provide the known intracellular IHC and OHC steady-state potentials in the absence of sound stimulus of -45 and $-70 \mathrm{mV}$, respectively (Cody and Russell 1987; Russell and Sellick 1978). Similarly, the effective cross-section capacitance of stria vascularis was used to obtain known values of cochlear microphonics at node 1 (Misrahy et al. 1958; Tasaki 1957) as analysed previously (Mistrik et al. 2009). Finally, the longitudinal GJ coupling between cross-sections in this coarse-grained model (300 cross-sections in the model represent 3,000 rows of hair cells in the cochlea) was chosen to obtain the observed frequency tuning of the extracellular receptor potential in the organ of Corti (Fridberger et al. 2004). In this configuration, the effective values of GJ resistors in the organ of Corti (radial and longitudinal) are $10 \times$ smaller than those of supporting cells, in a reasonable agreement with experimental observations (Lagostena et al. 2001; Santos-Sacchi 1991). There are relatively few free parameters in this model: the major uncertainties which are not constrained by experimental data are the values of the GJ resistances between cochlear compartments.

\section{Computational model of current flow in the cochlea}

The described circuit with 12 nodes in each of 300 crosssections is very complex. This makes the determination of the 3,600 nodal voltages computationally very demanding. Their time dependence is given by the matrix equation

$$
\mathrm{CdV} / \mathrm{dt}=-\mathrm{GV}+\mathrm{I}_{\text {ind }}
$$

where $\mathrm{V}$ is the vector of nodal voltages and $\mathrm{C}$ and $\mathrm{G}$ are the matrices of known capacitances and conductances (including the contributions from the MET channels), respectively. $I_{\text {ind }}$ is the vector of known independent current and voltage sources used for self-consistent construction of equations (see Mistrik et al. 2009) and including the endocochlear potential $\left(\mathrm{V}_{\mathrm{SV}}\right)$ and inner and outer hair cell electrochemical potassium potentials $\left(\mathrm{V}_{\mathrm{IHC}}\right.$ and $\mathrm{V}_{\mathrm{OHC}}$, respectively) at each cross-section.

The analysis of the effect of reduced GJ conductivity on the $\mathrm{OHC}$ transmembrane potential required to calculate the voltages at nodes 3 and 11 (Figure 1C) at all 300 cross-sections. To reduce the computational load associated with a large size of the $\mathrm{C}, \mathrm{G}$ matrices $(3,600 \times 3,600)$, Eq. 1 was solved in the frequency domain rather than in the time domain. The maximal amplitude and phase, instead of the full time course of nodal voltages were calculate using two simplifying assumptions: (1) that the sound stimulus was sinusoidal (single-tone with frequency $\mathrm{f}=\omega / 2 \pi)$; and (2) that the evoked potential $\Delta \mathrm{V}\left(=\mathrm{V}-\mathrm{V}_{0}\right)$ results from a small perturbation of the steady-state potential $\mathrm{V}_{0}$ (in the absence of a sound stimulus). As a result, the equations are tractable, linearised equations. The sound-evoked nodal potentials $\Delta \mathrm{V}(x, \omega)$ at every frequency and distance $x$ from the stapes is then given by the matrix equation

$$
\Delta \mathrm{V}(x, \omega)=\left(-\mathrm{j} \omega \mathrm{C}+\mathrm{G}_{\mathrm{o}}\right)^{-1} \gamma \mathrm{e}^{-\mathrm{j} \theta} \mathrm{G}_{0}{ }^{-1} \mathrm{I}
$$

where $G_{0}$ is the matrix of steady-state conductances, $G_{0}{ }^{-1}$ signifies matrix inversion, $\gamma=\gamma(x, \omega)$ and $\theta=\theta(x, \omega)$ represent the amplitude and phase perturbation of the steady state apical transducer conductance produced by the $\mathrm{BM}$ displacement at a distance $x$ from the stapes. In this small signal approximation, $\gamma$ at the best position was taken to be $10 \%$ of the resting transducer conductance. The excursion of potential across the OHC membrane, the perturbed electric field $\Delta \mathrm{E}_{\mathrm{OHC}}$, which prestin in the membrane experiences, was then determined as the difference between the $\Delta \mathrm{V}$ at nodes 3 and 11

$$
\Delta \mathrm{E}_{\mathrm{OHC}}(\mathrm{x}, \omega)=\Delta \mathrm{V}_{\text {node3 }}(\mathrm{x}, \omega)-\Delta \mathrm{V}_{\text {node11 }}(\mathrm{x}, \omega)
$$

for every section at distance $x$ from the stapes. The large matrices were generated from a connectivity Table 1 automatically using the modified nodal analysis approach. 
TABLE 1

\begin{tabular}{|c|c|c|c|c|c|c|}
\hline \multicolumn{7}{|c|}{ Parameters used in simulations } \\
\hline Circuit element & Description & Node 1 & Node 2 & Value & Connectivity & Data source \\
\hline $\mathrm{R}_{\mathrm{Al}}$ & IHC apical resistance & 1 & 2 & $1.2 \mathrm{M} \Omega$ & - & Calculated from $\mathrm{R}_{\mathrm{BI}}$ \\
\hline $\mathrm{C}_{\mathrm{Al}}$ & IHC apical capacitance & 1 & 2 & $6 \mathrm{pF}$ & - & $\begin{array}{l}\text { (Lopez-Poveda and } \\
\text { Eustaquio-Martin 2006) }\end{array}$ \\
\hline $\mathrm{R}_{\mathrm{BI}}$ & IHC basal resistance & 2 & 4 & $5.5 \mathrm{M} \Omega$ & - & $\begin{array}{l}\text { (Lopez-Poveda and } \\
\text { Eustaquio-Martin 2006) }\end{array}$ \\
\hline $\mathrm{C}_{\mathrm{BI}}$ & IHC basal capacitance & 2 & 6 & $60 \mathrm{pF}$ & - & (Raybould et al. 2001) \\
\hline$V_{I H C}$ & IHC ionic potential & 4 & 6 & $-100 \mathrm{mV}$ & - & \\
\hline $\mathrm{R}_{\mathrm{SL}}$ & $\begin{array}{l}\text { Resistance of spiral } \\
\text { lamina }\end{array}$ & 6 & 10 & $25 \mathrm{M} \Omega$ & - & \\
\hline $\mathrm{R}_{\mathrm{LS}}$ & $\begin{array}{l}\text { Resistance of scala } \\
\text { tympani }\end{array}$ & 10 & 0 & $25 \mathrm{M} \Omega$ & $25 \mathrm{M} \Omega$ & \\
\hline $\mathrm{R}_{\mathrm{AO}}$ & OHC apical resistance & 1 & 3 & 1.4-70 M $\Omega$ & & Calculated from $\mathrm{R}_{\mathrm{BO}}$ \\
\hline $\mathrm{C}_{\mathrm{AO}}$ & OHC apical capacitance & 1 & 3 & $10.5 \mathrm{pF}$ & - & Calculated from $\mathrm{C}_{\mathrm{BO}}$ \\
\hline $\mathrm{R}_{\mathrm{BO}}$ & $\mathrm{OHC}$ basal resistance & 3 & 5 & $0.6-30 \mathrm{M} \Omega$ & - & $\begin{array}{l}\text { (Housley and Ashmore 1992; } \\
\text { Mammano and Ashmore 1996; } \\
\text { Preyer et al. 1996) }\end{array}$ \\
\hline $\mathrm{R}_{\mathrm{CD}}$ & $\mathrm{OHC}$ lateral resistance & 3 & 11 & $100 \mathrm{M} \Omega$ & & $\begin{array}{l}\text { Lower bound from leak } \\
\text { resistance of OHCs }\end{array}$ \\
\hline $\mathrm{C}_{\mathrm{BO}}$ & OHC lateral capacitance & 3 & 11 & $176 \mathrm{pF}$ & - & $\begin{array}{l}\text { (Housley and Ashmore } \\
\text { 1992) }\end{array}$ \\
\hline $\mathrm{V}_{\mathrm{OHC}}$ & $\mathrm{OHC}$ ionic potential & 5 & 7 & $-100 \mathrm{mV}$ & - & \\
\hline $\mathrm{R}_{\mathrm{SN}}$ & $\begin{array}{l}\text { Longitudinal resistance } \\
\text { in space of Nuel }\end{array}$ & 11 & 11 & & $0.05 \mathrm{M} \Omega$ & Estimate from geometry \\
\hline$C_{D C}$ & $\begin{array}{l}\text { Capacitance of Deiter's } \\
\text { cell }\end{array}$ & 9 & 11 & $180 \mathrm{pF}$ & & $\begin{array}{l}\text { (Lagostena et al. 2001; } \\
\text { Santos-Sacchi 1991) }\end{array}$ \\
\hline $\mathrm{R}_{\mathrm{DC}}$ & $\begin{array}{l}\text { Resistance of Deiters' } \\
\text { cell }\end{array}$ & 7 & 9 & $0.1 \mathrm{M} \Omega$ & & " n n n \\
\hline $\mathrm{R}_{\mathrm{GJ}}, \mathrm{R}_{\mathrm{GJL}}$ & $\begin{array}{l}\text { Resistance of gap } \\
\text { junction }\end{array}$ & 9 & 12 & $\begin{array}{l}0.01 \mathrm{M} \Omega \\
\quad\left(\text { for } R_{\mathrm{GJ}}\right)\end{array}$ & $\begin{array}{l}0.01 \mathrm{M} \Omega \\
\left(\text { for } R_{\mathrm{GJL}}\right)\end{array}$ & 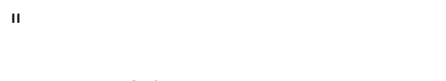 \\
\hline $\mathrm{R}_{\mathrm{CC}}$ & $\begin{array}{l}\text { Lumped resistance } \\
\text { of Claudius cells }\end{array}$ & 12 & 0 & $0.1 \mathrm{M} \Omega$ & & $\begin{array}{l}\text { Estimated from Hensen } \\
\text { cell values (Lagostena } \\
\text { et al. 2001; Santos-Sacchi } \\
\text { 1991) }\end{array}$ \\
\hline $\mathrm{C}_{\mathrm{CC}}$ & $\begin{array}{l}\text { Lumped capacitance } \\
\text { of Claudius cells }\end{array}$ & 12 & 0 & $150 \mathrm{pF}$ & & $\begin{array}{l}\text { Estimated from Hensen } \\
\text { cell values (Lagostena } \\
\text { et al. 2001; Santos-Sacchi } \\
\text { 1991) }\end{array}$ \\
\hline$v_{S V}$ & $\begin{array}{l}\text { Endocochlear potential } \\
\text { in stria vascularis }\end{array}$ & 1 & 8 & $80 \mathrm{mV}$ & - & \\
\hline $\mathrm{C}_{\mathrm{SV}}$ & $\begin{array}{l}\text { Stria vascularis } \\
\text { capacitance }\end{array}$ & 1 & 0 & $5,000 \mathrm{pF}$ & - & (Mistrik et al. 2009) \\
\hline $\mathrm{R}_{\mathrm{SV}}$ & $\begin{array}{l}\text { Stria vascularis } \\
\text { resistance }\end{array}$ & 8 & 0 & $0.1 \mathrm{M} \Omega$ & $0.1 \mathrm{M} \Omega$ & \\
\hline
\end{tabular}

"Node 1 " and "Node 2" indicate the location of element in the circuits in figure 1 and "Value" its electrical magnitude; "Connectivity" indicates whether the node 1 is coupled longitudinally in the adjacent cross-sections, and if so, a value of the element if appropriate is given. The data sources are given in the last column

The full derivation has been described previously (Mistrik et al. 2009). The computations were carried out in Matlab (ver. 7.04, The Mathworks, Natick, MA, USA) using conventional matrix methods and provided stable and unique solutions.

\section{RESULTS}

\section{Generation of $\mathrm{OHC}$ gain functions}

Figure 2 shows the generation of the input-output functions in the model. First, the network response to a
$1 \mathrm{kHz}$ tone was considered and the amplitude and phase, calculated according to Eqs. 2 and 3, are shown in Figure 2A, B. The dotted line represents the input BM envelope used to control the hair cell transducer conductances and the continuous line shows the $\mathrm{OHC}$ transmembrane potential, $\Delta \mathrm{E}_{\mathrm{OHC}}$, at all positions along the cochlear partition. In Figure $2 \mathrm{~A}, \Delta \mathrm{E}_{\mathrm{OHC}}$ is plotted normalised to unity for comparison with the BM amplitude.

The $\mathrm{OHC}$ transmembrane potential, $\Delta \mathrm{E}_{\mathrm{OHC}}$, indicates broader electrical tuning than its mechanical input. The broadening can be traced to longitudinal coupling between 
A

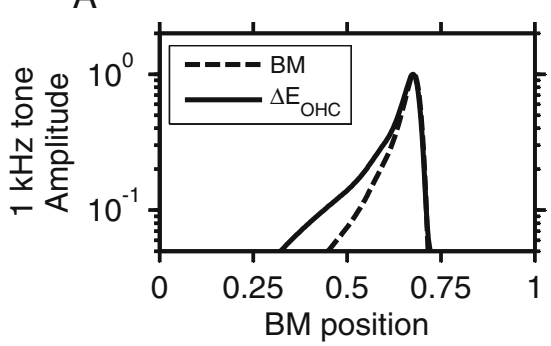

C

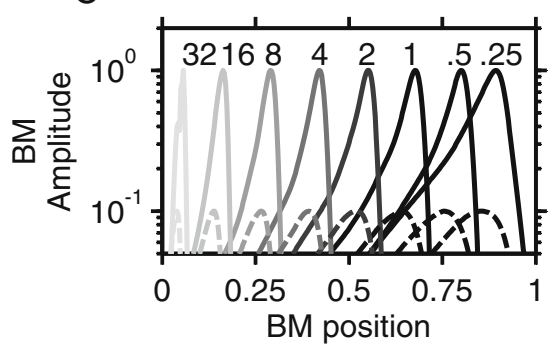

E

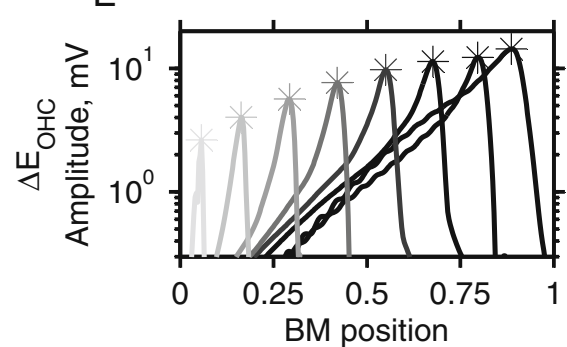

G

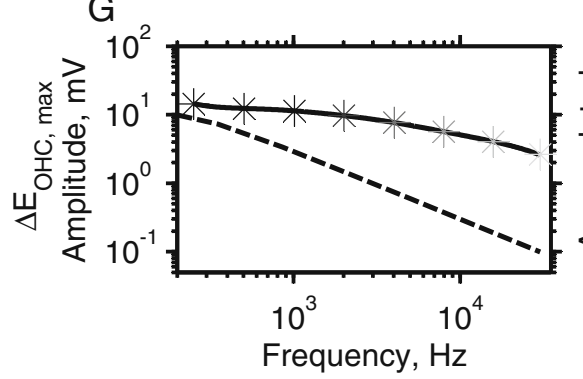

\section{B}

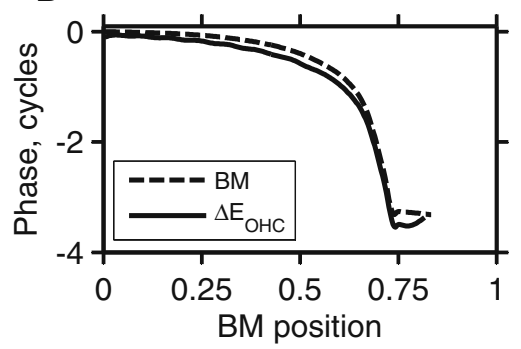

D

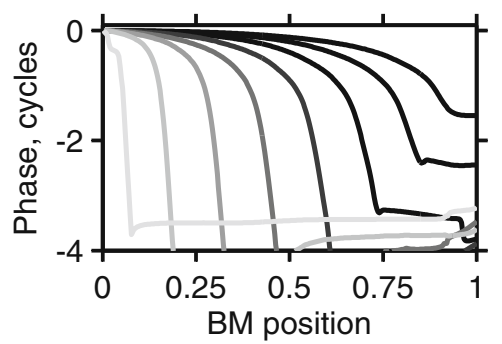

$\mathrm{F}$

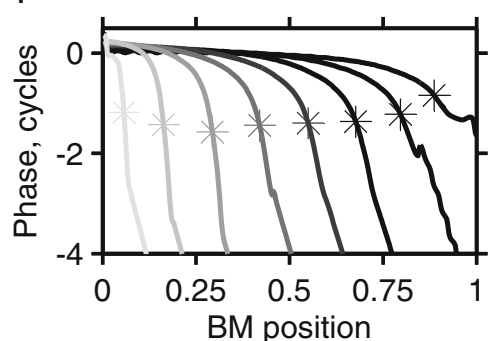

$\mathrm{H}$

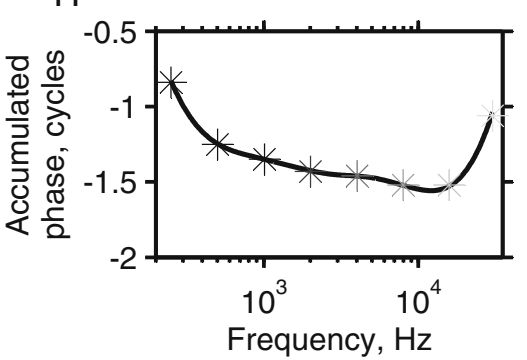

FIG. 2. The generation of cochlear gain functions for the $\mathrm{OHC}$ transmembrane potential, $\Delta \mathrm{E}_{\mathrm{OHC} \text {,max. }} \mathbf{A}$ and $\mathbf{B}$ An overlay of normalised BM travelling wave (broken line) and $\Delta \mathrm{E}_{\mathrm{OHC}}$ tonotopic pattern (solid line) produced by a $1 \mathrm{kHz}$ tone (A amplitude, $\mathbf{B}$ phase). $\Delta \mathrm{E}_{\mathrm{OHC}}(\mathrm{x})$ is the $\mathrm{OHC}$ receptor potential between nodes 3 and 11 at the BM position $x(0<x<1)$, relative to the stapes. $\mathbf{C}$ and $\mathbf{D}$ An overlay of eight BM travelling waves corresponding to frequencies of $0.25,0.5,1,2,4,8$, 16 and $32 \mathrm{kHz}$ (C amplitude, D phase). For comparison, the travelling waves evoked in the tuned (solid line) and detuned (broken line) cochlea are both plotted. The amplitude of the detuned BM travelling wave is $20 \mathrm{~dB}$ smaller than in the tuned case. $\mathbf{E}$ and $\mathbf{F}$ An overlay of eight tonotopic patterns of $\Delta \mathrm{E}_{\mathrm{OHC}}$ generated using the tuned BM travelling waves from panels $\mathbf{C}$ and $\mathbf{D}$. For each tone, the maximal amplitude (E) as well as the phase accumulated in the corresponding best position (F) are both indicated (asterisk). $\mathbf{G}$ The frequency dependence of the maximum $\mathrm{OHC}$ transmembrane poten-

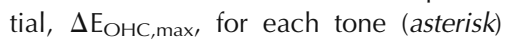
derived from $\mathbf{E}$. The case of an isolated $\mathrm{OHC}$ is also shown (broken line), where the external potential would be $0 \mathrm{mV}$. $\mathbf{H}$ The frequency dependence of the phase accumulated at the best position. The responses in this and subsequent figures correspond to low level acoustic stimuli (20-40 dB SPL), permitting computations to be made from a linearised model (Eq. 2). the sections. In addition, the phase of the electrical response is delayed by approximately $90^{\circ}$ relative to the mechanical input as would be expected for a voltage generated across the capacitance of the $\mathrm{OHC}$ membrane (Figure 1B).

The amplitude and phase of the BM travelling waves, generated by single tones with a variety of logarithmically spaced best frequencies between 0.25 and $30 \mathrm{kHz}$, are shown in Figure 2C, D. The corresponding OHC transmembrane potentials, $\Delta \mathrm{E}_{\mathrm{OHC}}(x, \omega)$, are shown in Figure 2E, F. The maximal values as well as the accumulated phases at corresponding best position for each tone are indicated by an asterisk (*). Finally, $\Delta \mathrm{E}_{\mathrm{OHC}, \max }(\omega)$, the maximum value of $\Delta \mathrm{E}_{\mathrm{OHC}}(\mathrm{x}, \omega)$ at each stimulus frequency $\omega$ is shown in Figure $2 \mathrm{G}$ and the corresponding accumulated phase in Figure 2H. Such plots, connecting the mechanical input and electrical output, represent the gain functions (amplitude and accumulated phase) for the cochlea as a whole.

An examination of the frequency dependence of the $\mathrm{OHC}$ amplitude in Figure $2 \mathrm{G}$ reveals an attenuation of the response by $6 \mathrm{~dB} /$ decade with increasing frequency. For comparison, the frequency dependence of an isolated OHC is shown on the same plot, where the DC asymptote has been scaled to the same point. In this case, the external potential is $0 \mathrm{mV}$, whereas for cell coupled into a network, the external potential will depend on all the other elements in the circuit, and $\Delta \mathrm{E}_{\mathrm{OHC} \text {,max }}$ will be modified accordingly. The isolated cell exhibits a roll off as $1 / \mathrm{f}$, characteristic of a cell with a single RC membrane time constant with an attenuation of $21 \mathrm{~dB} /$ decade (or equivalently $6 \mathrm{~dB} /$ octave). As 

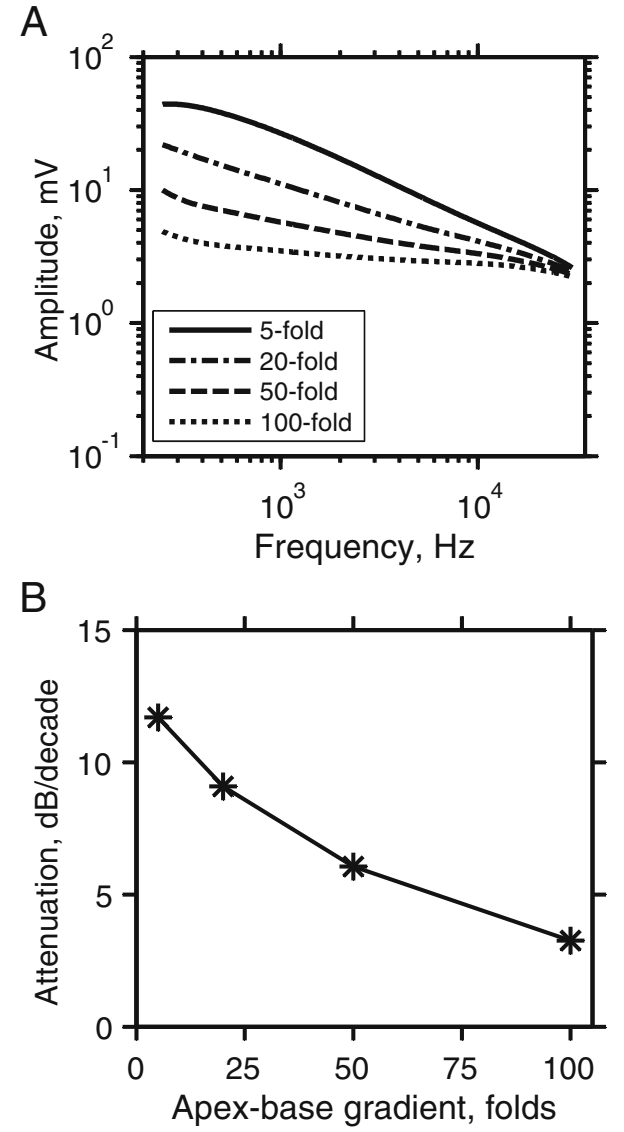

C

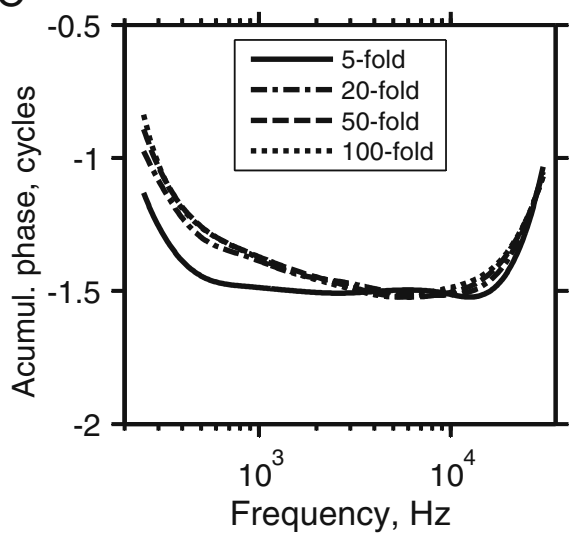

FIG. 3. $\mathrm{OHC}$ gain function and the effect of the apex base gradient in the $\mathrm{OHC}$ membrane conductance. A The frequency dependence of $\Delta \mathrm{E}_{\mathrm{OHC}}$, max for different apex-base gradients (-, fivefold increase between base and apex conductance; -.-, 20-fold; - , 50-fold; ..., 100-fold). B The dependence of the $\Delta \mathrm{E}_{\mathrm{OHC}}$ max attenuation in the $0.25-30 \mathrm{kHz}$ range on the tonotopic conductance gradient. The slope is computed from the results in A. C The frequency dependence of the phase accumulated at the best BM position for different apex base gradients.

argued previously (Mistrik et al., 2009) the reduced attenuation of $\Delta \mathrm{E}_{\mathrm{OHC} \text {, max }}$ in a cochlear network arises from the gradient in OHC conductance which increases from cochlear apex to cochlear base and the GJ coupling which allows the extracellular currents to build up nonzero extracellular potentials around the OHCs.
The effect of the $\mathrm{OHC}$ conductance gradient on the attenuation of the $\mathrm{OHC}$ transmembrane potential is shown in Figure 3A. It demonstrates that a gradient exponentially increasing the conductance by fivefold from apex to base would reduce the $\mathrm{OHC}$ attenuation from $21 \mathrm{~dB} /$ decade (the isolated cell case) to $11.6 \mathrm{~dB} /$ decade. A 100-fold apex-base conductance increase would reduce the attenuation to only $3 \mathrm{~dB} / \mathrm{dec}$ ade (Figure 3B), even though the phase accumulated at the best frequency is affected only to small extent by such a gradient (Figure 3C). In subsequent calculations, a 50fold apex-base conductance increase was used as it corresponds to the experimentally observed tonotopic variation in $\mathrm{OHC}$ conductances (Housley and Ashmore 1992; Mammano and Ashmore 1996; Preyer et al. 1996). The OHC membrane capacitances were kept constant along the cochlea because, experimentally, $\mathrm{OHC}$ capacitances vary only threefold along the longitudinal tonotopic axis, and therefore by a relatively minor factor compared to the conductance changes.

\section{Cx26 mutations reducing intercellular connectivity (35delG)}

The $\mathrm{OHC}$ gain functions from Figure 2 (the frequency dependence of the $\mathrm{OHC}$ transmembrane potential $\left.\Delta \mathrm{E}_{\mathrm{OHC}, \max }\right)$ were used to assess the effect of $\mathrm{Cx} 26$ mutations. The changes in specific conductance of GJ were taken from the literature. For example, the residual permeability of the Cx26 mutant F83L for monovalent ions such as $\mathrm{K}^{+}$is reported to be $72 \%$ of the wild-type (Bruzzone et al. 2003 ) and that of M34T 11\% of the wild-type (Bicego et al. 2006). Furthermore, mutations such as 35delG, V37I, W77R, L90P, S113R, M163V, 167delT, and R184P result in a complete loss of function with residual conductivity $\leq 1 \%$ of the wild-type values (Bicego et al. 2006; Bruzzone et al. 2003). Other mutations, such as V84L, although reducing the conductivity for metabolites (Beltramello et al. 2005), were not considered here.

Reduced GJ conductivity was simulated in the model by increasing the value of corresponding resistors $R_{\mathrm{GJ}}$ and $R_{\mathrm{GJL}}$ representing, respectively, radial and longitudinal intercellular conductance between supporting cells in the organ of Corti. A 10\% increase in either or both resistance values (to $R_{\mathrm{GJ}}, R_{\mathrm{GJL}}=0.1 \mathrm{M} \Omega$ ) had little effect on the frequency dependence of $\Delta \mathrm{E}_{\mathrm{OHC} \text {,max }}$ amplitude and accumulated phase (Figure 4A and B, respectively). Therefore, we conclude that mutations such as M34T (with $11 \%$ residual conductance) or $\mathrm{F} 83 \mathrm{~L}$ (with $72 \%$ residual conductance) are unlikely to reduce $\Delta \mathrm{E}_{\mathrm{OHC} \text {,max }}$ and, by implication, would not compromise $\mathrm{OHC}$ electromotility.

On the other hand, mutations such as 35delG, V37I, W77R, L90P, S113R, delE120, M163V, R184P, and $235 \mathrm{delC}$ with a complete loss of permeability (conductance decreasing to $0.1 \%$ of wild-type value or, equivalently, setting $R_{\mathrm{GJ}}, R_{\mathrm{GJL}}=10 \mathrm{M} \Omega$ ) significantly reduced the 


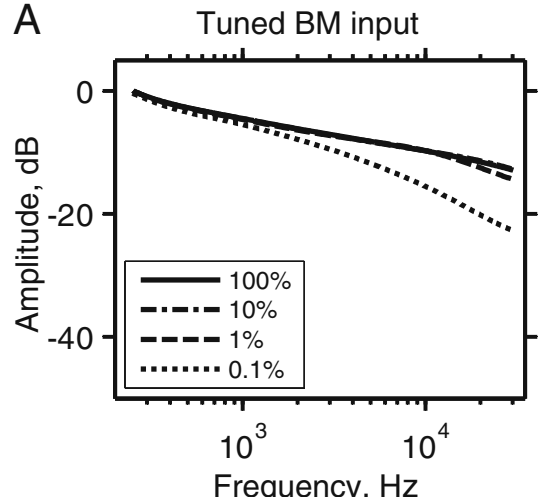

B

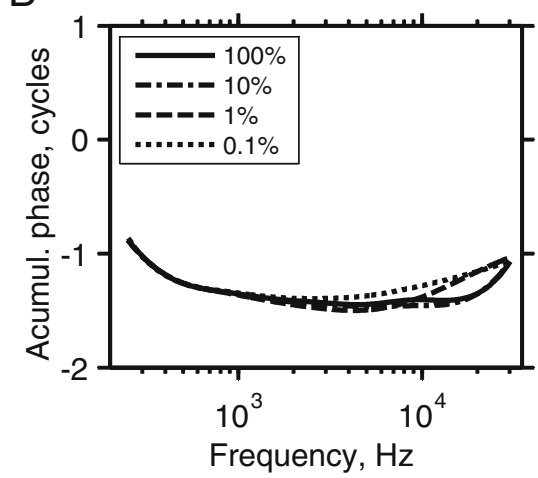

C

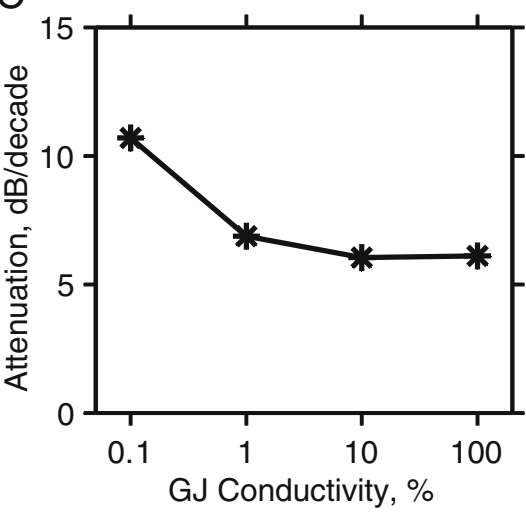

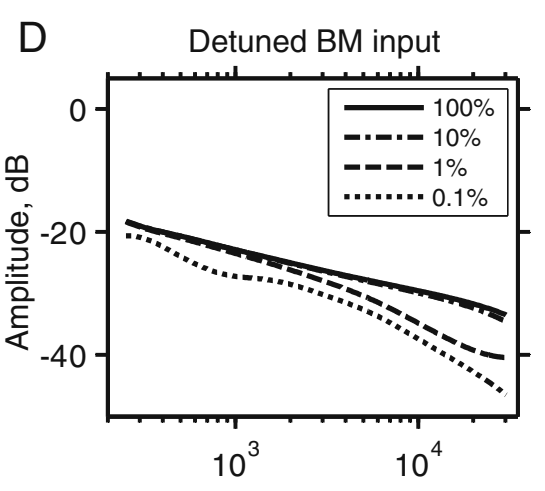

Frequency, $\mathrm{Hz}$
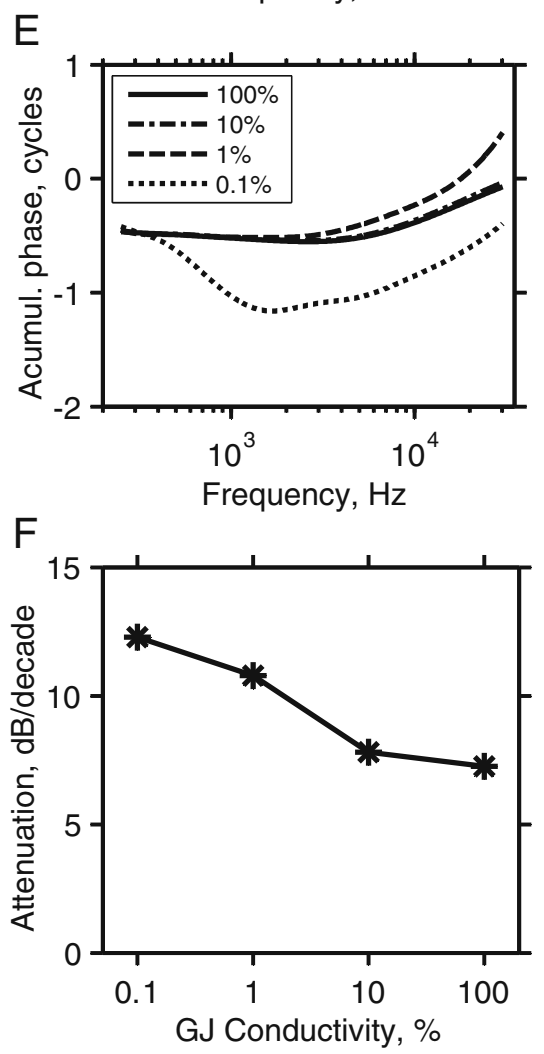

FIG. 4. The effect of 30delG-like mutations on the $\mathrm{OHC}$ gain functions. $\mathbf{A}$ and $\mathbf{B}$ The frequency dependence of the amplitude and accumulated phase of $\Delta \mathrm{E}_{\mathrm{OHC}}$, max for different residual GJ conductance $(100 \%,-; 10 \%,-.-; 1 \%,-, 0.1 \%$...). The G) conductance was decreased by increasing the value of $R_{\mathrm{GJ}}$ and $R_{\mathrm{GJL}}$. This represents the situation of 30 delG-like mutations reducing intercellular conductivity between supporting cells in the organ of Corti. Tuned BM travelling waves ware used as the input for the calculation of $\Delta \mathrm{E}_{\mathrm{OHC}}$. C The dependence of the attenuation of amplitude in the $0.25-30 \mathrm{kHz}$ frequency range on the GJ conductivity. D and E Like $\mathbf{A}$ and $\mathbf{B}$ but with detuned BM travelling wave as input (and as a result the amplitude is $20 \mathrm{~dB}$ smaller than in Figure 2C). F The dependence of the attenuation on the GJ conductivity (a detuned BM was used as input).
$\Delta \mathrm{E}_{\mathrm{OHC}, \max }$ amplitude at frequencies above $1 \mathrm{kHz}$ (Figure 4A). The corresponding increase in the attenuation from 6.1 to $10.7 \mathrm{~dB} /$ decade over the $0.25-30 \mathrm{kHz}$ range (Figure 4C) can be explained by high frequency currents shunting to the ground (the perilymph) through the membrane capacitance of the supporting cells. It should be pointed out that this calculation is semiquantitive only. A larger value of $R_{\mathrm{GJ}}$ is required to compensate for the supporting cell values chosen here: the precise network values are unknown experimentally. Qualitatively, at frequencies above those corresponding to the characteristic membrane time constant of the supporting cell network (here formed by $\mathrm{R}_{\mathrm{CC}}$ and $\mathrm{C}_{\mathrm{CC}}$ ) most of the current gated by the transducer will pass to ground through the membrane capacitances.

A reduced $\Delta \mathrm{E}_{\mathrm{OHC} \text {,max }}$ amplitude implies that the electromotile forces amplifying initial mechanical BM displacements are therefore likely to be much smaller. The simplest assumption is that the feedback forces are reduced in proportion. Nevertheless, implementing a stable feedback to the cochlear mechanics means significantly increasing the complexity of a cochlear mechanical model. For this reason, the implied reduced cochlear amplification was modelled by using a detuned rather than a sharply tuned BM displacement as the input for electrical calculations (Figure 2C, dashed lines). The BM input in this case corresponded to a quasipassive cochlea model where the $\mathrm{OHC}$ feedback parameter, $\lambda$, used in Mammano-Nobili model is reduced from 1.2 to 0.05 (Mammano and Nobili 1993). The BM displacement with $\lambda=$ 0.05 will be referred to below as a 'detuned' input. The BM envelope still exhibited phase accumulation and frequency dependence, but the feedback was chosen to reduce the amplitude by $20 \mathrm{~dB}$.

The gain functions (amplitude and accumulated phase) obtained for reduced conductances with such 
detuned BM input are shown in Figure 4D, E. The derived dependence of the amplitude attenuation on the GJ conductance (Figure 4F) indicated a maximal value of $12.3 \mathrm{~dB} /$ decade over the $0.25-30 \mathrm{kHz}$ range for the mutations with $0.1 \%$ conductivity of wild-type. It should be noted that the phase accumulated at the best frequencies $>300 \mathrm{~Hz}$ was increased (Figure 4E). Such an increase in phase accumulation arises from a parallel current injection into larger number of cross-sections as a result of a detuned mechanical input, and hence an increased filtering due the capacitance currents delaying responses in the circuit. It might be anticipated that such OHC receptor potentials would be further attenuated due to the cancelling effect of neighbouring $\mathrm{OHC}$ rows (Dallos and Cheatham 1976), but this would have required a finer grain model to investigate the point.

\section{Cx26 mutations which reduce intercellular and extracellular conductivity (R75W)}

It is well known that a functional epithelial cell gap junction system is essential for normal development of the inner ear as it facilitates necessary intercellular signalling (Nickel and Forge 2008). It is therefore not surprising that some GJ mutations lead to developmental malformations of the organ of Corti. For example, R75W significantly reduces the space of Nuel, the extracellular fluid-filled compartment surrounding $\mathrm{OHCs}$ (Kudo et al. 2003). Such defect could easily affect both the

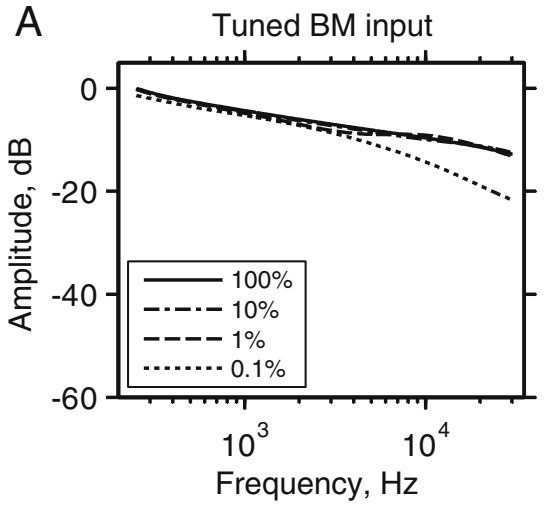

B

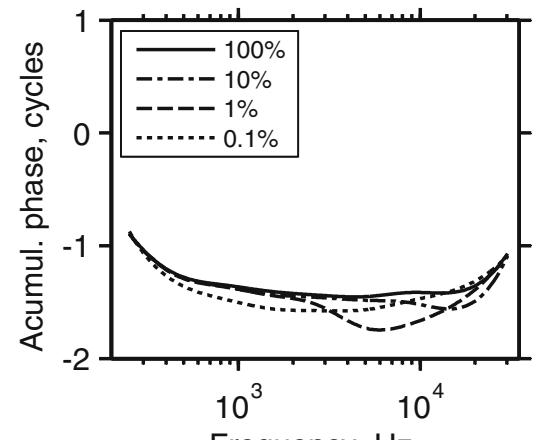

Frequency, $\mathrm{Hz}$

C

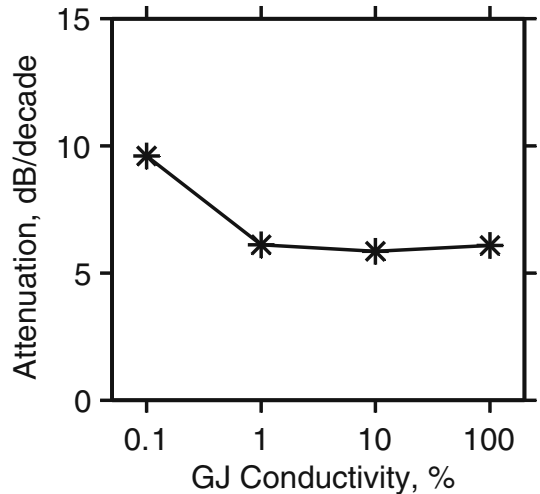

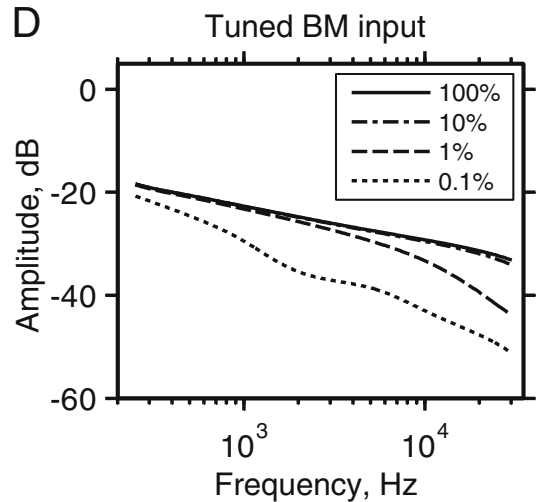

E

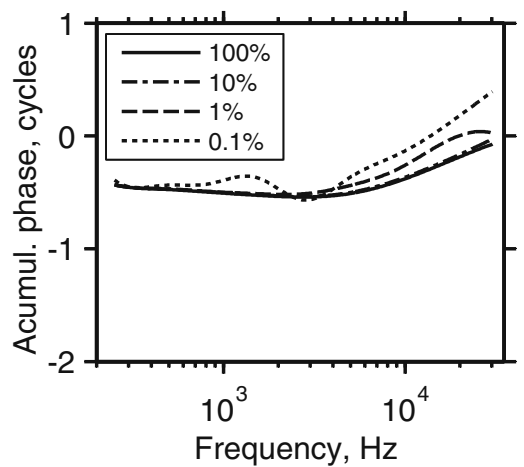

F

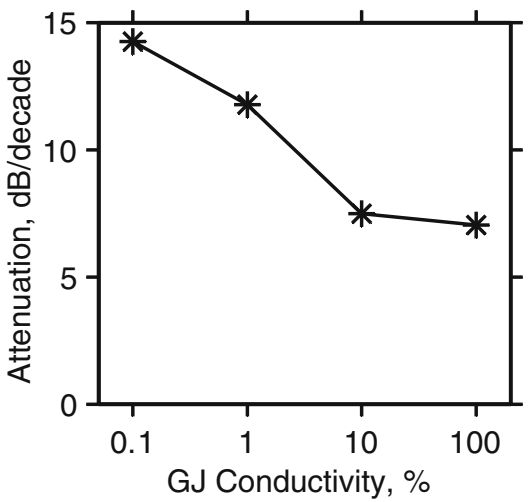

FIG. 5. The effect of R75W-like mutations on the $\mathrm{OHC}$ gain functions. The same as in Figure 4 but in addition to $R_{\mathrm{G} J}$ and $R_{\mathrm{GJL}}, R_{\mathrm{SN}}$ was also increased in these simulations to mimic reduced extracellular conductivity through the space of Nuel $(0.1 \%)$. 
micromechanics of the cochlear partition and extracellular conductivity in the organ of Corti. In what follows, we shall explore the electrical consequences of the mutation.

Such additional (indirect) effect of changed extracellular conductivity was investigated by increasing the value of the $R_{\mathrm{SN}}$ resistor connecting the node 11 between adjacent cross-sections (Figure 1D) and representing longitudinal extracellular conductivity through the space of Nuel. The gain functions (amplitude and accumulated phase) obtained with conductances reduced to $0.1 \%$ of wild-type values $\left(R_{\mathrm{GJ}}, R_{\mathrm{GJL}}=10 \mathrm{M} \Omega, R_{\mathrm{SN}}=50 \mathrm{M} \Omega\right)$ and a sharply tuned mechanical input are shown in Figure $5 \mathrm{~A}, \mathrm{~B}$, respectively. Figure $5 \mathrm{C}$ hows that the attenuation at frequencies above $5 \mathrm{kHz}$ is increased relative to the wild-type $(9.6 \mathrm{~dB} /$ decade for the mutant against $6.1 \mathrm{~dB} /$ decade for the wild-type over a 0.25 $30 \mathrm{kHz}$ range). Such attenuation is less than that obtained for GJ mutations producing only reduced intercellular conductivity (e.g. Figure 4C, showing an attenuation of $10.7 \mathrm{~dB} /$ decade). The explanation is that more current will always flow through the extracellular path through the space of Nuel at high frequencies since $R_{\mathrm{SN}}$ is small. However, if $R_{\mathrm{SN}}$ is increased as the space fails to open, longitudinal current is shunted to earth across RDC and the attenuation of the potential across the OHC membrane is decreased.

When reduced electro-mechanical feedback was implemented using a detuned BM input (the case of $\mathrm{R} 75 \mathrm{~W}$ ), the $\mathrm{OHC}$ attenuation was increased to $14.2 \mathrm{~dB} /$ decade over the $0.25-30 \mathrm{kHz}$ range (Figure $5 \mathrm{~F}$ ). This value is larger than that obtained when only intercellular conductivity was reduced (Figure 4F, $12.3 \mathrm{~dB} /$ decade). Such in silico findings emphasises the importance of the low-resistance pathway through the space of Nuel in the maintenance of electromotile forces.

\section{Cx26 and Cx30 mutations and endocochlear potential}

In addition to a reduction of the gap junction conductivity in the organ of Corti, it is known that the targeted deletion of $\mathrm{Cx} 26$ can lead to a reduction of endocochlear potential (EP) from +80 to $+40 \mathrm{mV}$, and to a reduction in endolymph potassium concentrations (Cohen-Salmon et al. 2002). It is also known that $\mathrm{Cx} 30$ deletions in stria vascularis can reduce $\mathrm{EP}$ to $0 \mathrm{mV}$ (Teubner et al. 2003).

The effect of reducing $\mathrm{EP}$ on $\Delta \mathrm{E}_{\mathrm{OHC} \text {, max }}$ was simulated most simply by reducing the value of the battery $\mathrm{V}_{\mathrm{SV}}$ and changing $\mathrm{V}_{\mathrm{OHC}}, \mathrm{V}_{\mathrm{IHC}}$ in order to maintain intracellular resting potentials in the hair cells. The results for both Cx26 and Cx30-type deletions with tuned and detuned mechanical input are shown in Figure $6 \mathrm{~A}$ and $\mathrm{B}$, respectively. The amplitude reduction was uniform across the whole frequency range and no increase in the attenuation was observed even in the case of a tuned mechanical input. The decrease was relatively small for the Cx26 simulated deletion $(4.3 \mathrm{~dB})$ but reached $10.2 \mathrm{~dB}$ for the simulated $\mathrm{Cx} 30$ deletion (Figure 6C). There was no effect on the accumulated phase (data not shown).

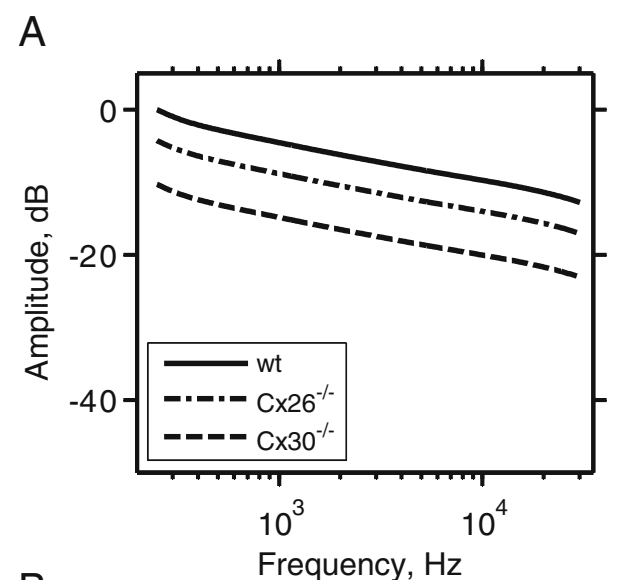

B
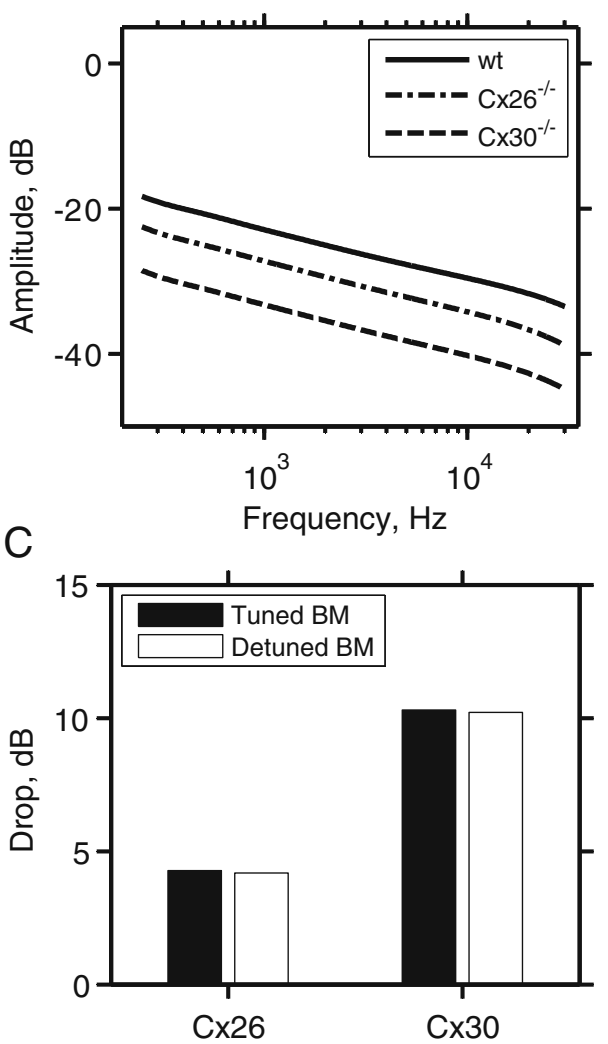

FIG. 6. The effect of reducing endocochlear potential. Non-functional connexins are associated with a decrease of the endocochlear potential battery $\left(\mathrm{V}_{\mathrm{SV}}\right)$ and of $\mathrm{K}^{+}$electrochemical potentials $\left(\mathrm{V}_{\mathrm{OHC}}\right.$ and $\mathrm{V}_{\mathrm{IHC}}$ for OHC and IHC, respectively), see Table 1 . In the case of $\mathrm{Cx} 26^{-1-}$, $\mathrm{V}_{\mathrm{SV}}$ was reduced from 80 to $40 \mathrm{mV}$ and both $\mathrm{V}_{\mathrm{OHC}}$ and $\mathrm{V}_{\mathrm{IHC}}$ from -100 to $-70 \mathrm{mV}$ to maintain stable intracellular resting potentials. Similarly, in the case of $\mathrm{C} \times 30^{-/-}, \mathrm{V}_{\mathrm{SV}}$ was reduced to $0 \mathrm{mV}$ and $\mathrm{V}_{\mathrm{OHC}}$ and $\mathrm{V}_{\mathrm{IHC}}$ to $-55 \mathrm{mV}$. The frequency dependence of the $\mathrm{OHC}$ receptor potential with A tuned and $\mathbf{B}$ detuned mechanical input in the presence (wt) or absence of any of the two connexins. C The amplitude reduction due to a deletion of $\mathrm{Cx} 26$ or $\mathrm{Cx} 30$. Whether the BM was sharply tuned or detuned had no effect. 
A

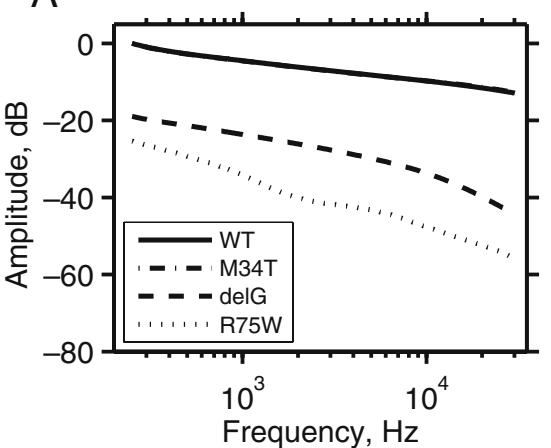

C

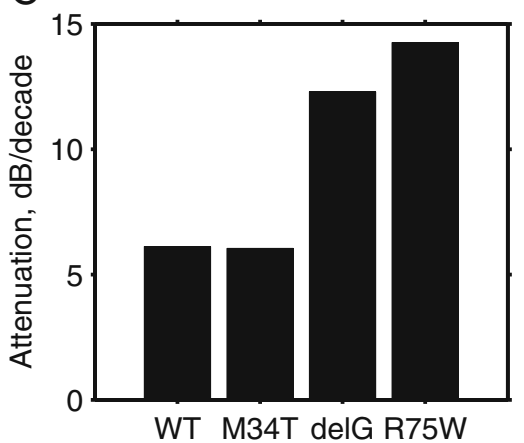

$\mathrm{B}$

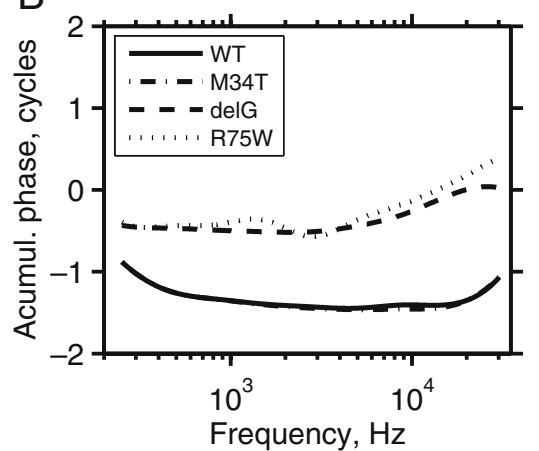

D

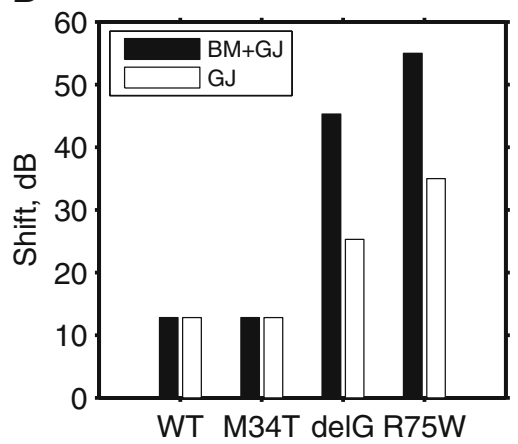

FIG. 7. Connexin mutations can reduce the $\mathrm{OHC}$ receptor potential. $\mathbf{A}$ and $\mathbf{B}$ The frequency dependence of the amplitude (A) and accumulated phase (B) for different Cx26 mutations. The curve for M43T was obtained with a tuned BM input and $10 \%$ residual G) conductivity $\left(R_{\mathrm{GJ}}=R_{\mathrm{GJL}}=\right.$ $1 \mathrm{M} \Omega$ ); delG with a detuned BM input, $0.1 \%$ residual G) conductivity $\left(R_{\mathrm{GJ}}=R_{\mathrm{GJ}}=\right.$ $100 \mathrm{M} \Omega$ ) and reduced circuit batteries as in Figure 6; R75W with a detuned BM input, $0.1 \%$ conductance $\left(R_{\mathrm{GJ}}=R_{\mathrm{GJ}}=100 \mathrm{M} \Omega\right)$, reduced extracellular conductivity in space of Nuel $\left(R_{\mathrm{SN}}=50 \mathrm{M} \Omega\right)$ and reduced circuit batteries as in Figure 6. C The amplitude attenuation for the $\mathrm{OHC}$ transmembrane receptor potential $\Delta \mathrm{E}_{\mathrm{OHC}}$, max at the 0.25 $30 \mathrm{kHz}$ range for different $\mathrm{C} \times 26$ mutations. The attenuation was calculated from the data in panel A. D The difference (shift) between the $\Delta \mathrm{E}_{\mathrm{OHC}}$, max amplitude generated by a $30 \mathrm{kHz}$ tone and a wt reference (250 Hz) for different Cx26 mutants. GJ the contribution purely due to electrical filtering through the cochlear network; $B M+G$ J the case with detuned mechanical input.

\section{Global effects of Cx26 mutations on the $\mathrm{OHC}$ receptor potential}

The effect of different classes of Cx26 mutations is presented in Figure 7. Here, the curves for wild-type and M43T were obtained with tuned BM input since the analysis in Figure 4 indicated that $10 \%$ residual GJ conductance (M43T) does not interfere with the feedback mechanism. The curve for delG (35delG-like mutations) was obtained with a $0.1 \%$ residual GJ conductance, a detuned BM and reduced circuit batteries (Figures 4 and 6). The same settings were used also for $\mathrm{R} 75 \mathrm{~W}$, but in addition with a residual $0.1 \%$ conductance through the space of Nuel, to mimic the absence of the extracellular current flow in the organ of Corti (Figures 5 and 6).

The examination of the frequency dependence of the amplitude and phase indicates a large variation in the effect of $\mathrm{Cx} 26$ mutations on the $\mathrm{OHC}$ receptor potential (Figure 7A, B). On the one hand, the responses for the M34T mutation is indistinguishable from the wild-type (the M34T result superimposes directly on top of the wildtype response). Such finding suggests that even a $11 \%$ residual GJ conductance in the in silico model of the organ of Corti is sufficient to maintain normal current flow and frequency dependence of the $\mathrm{OHC}$ receptor potential. Therefore, mutations such as M34T or F83L $(72 \%$ residual GJ conductance) are unlikely to reduce the $\mathrm{OHC}$ electromotility.
On the other hand, Cx26 mutations resulting in a complete loss of function (35delG, V37I, W77R, L90P, S113R, M163V, 167delT, R184P) and residual conductivity of $0.1-1 \%$ lead to a strong increase in the attenuation at frequencies above $5 \mathrm{kHz}$. The largest effect is found for the $\mathrm{R} 75 \mathrm{~W}$ mutation where increased attenuation is apparent already for frequencies $>1 \mathrm{kHz}$. This demonstrates the importance of the current flow through the space of Nuel, which is abolished by mutations resulting in a volume that does not open up during development.

The attenuation for different mutations is compared quantitatively in Figure 7C. It indicates that 35delG-like mutations double and $\mathrm{R} 75 \mathrm{~W}$ nearly triple the attenuation over the studied frequency range of $0.25-30 \mathrm{kHz}$. As the effect is largest at frequencies above $10 \mathrm{kHz}$, the effect of mutations at high frequencies is shown separately in Figure 7D. The figure compares the relative amplitude of the $\mathrm{OHC}$ receptor potential $\Delta \mathrm{E}_{\mathrm{OHC} \text {,max }}$ at $30 \mathrm{kHz}$ for wildtype and all mutants with respect to the wild-type amplitude at $250 \mathrm{~Hz}$. In the case of the wild-type, the expected reduction would be $12.8 \mathrm{~dB}$. On the other hand, the reduction of 26 and $35 \mathrm{~dB}$ was found for $35 \mathrm{delG}$ and R75W mutations, respectively, even before the effects of reduced electromotile feedback were included (and of 45 and $56 \mathrm{~dB}$, respectively, when included). Such a reduction indicates that electrical filtering due to $\mathrm{C} \times 26$ mutations could, at least at frequencies $\sim 30 \mathrm{kHz}$, nearly abolish the $40-60 \mathrm{~dB}$ gain provided by the $\mathrm{OHC}$ somatic amplifica- 
tion under normal physiological conditions (Ruggero and Rich 1991).

\section{DISCUSSION}

\section{A computational laboratory for studying connexin mutations}

The large-scale computational model of electrical currents used here provides an insight into the effect of circuit perturbations due to connexin mutations through their effects on ionic conductance. It offers, in addition, an opportunity to see how cells perform when coupled into a network, based on the data from single or small cell populations.

In a cochlear network circuit without any perturbations, the $\mathrm{OHC}$ receptor potential would be expected to show an attenuation of $6 \mathrm{~dB} /$ decade over the $0.25-30 \mathrm{kHz}$ range. Such a low value (in a comparison to $21 \mathrm{~dB} /$ decade for an isolated $\mathrm{OHC}$ ), results from the network distribution of current flow. The attenuation of $6 \mathrm{~dB} /$ decade is a quite conservative estimate, because the BM wave envelopes used as the input for the calculation of the frequency dependence of the potentials were all normalised to the same peak amplitude. However, there may be significant boosting of the BM amplitudes towards the cochlear base: as much as a $30 \mathrm{~dB}$ increase is predicted for some cochlear models (Ramamoorthy et al. 2007). This would provide a further 'flattening' of the $\mathrm{OHC}$ gain function. Thus, this minimal attenuation of the $\mathrm{OHC}$ transmembrane potential predicted from such cochlear models suggests that the OHC somatic electromotility can operate effectively in the whole auditory frequency range and not necessarily just in the low frequency range as originally predicted from measurements on isolated outer hair cells (Mammano and Ashmore 1996).

\section{Effect of Cx26 mutations}

The computational analysis of GJ mutation phenotypes performed here has revealed several indicative features of Cx26 mutations on current flow: (1) only a complete loss of function (0.1-1\% residual GJ conductance) significantly reduces the $\mathrm{OHC}$ receptor potential; (2) a reduction in the $\mathrm{OHC}$ receptor potential requires detuning of mechanical input, presumably due to weaker electro-mechanical feedback into the system; (3) Cx26 mutations can be simulated so that some affect intercellular while others affect also extracellular connectivity; and (4) the loss of $\mathrm{Cx} 26$ function ( uniform reduction of GJ conductivity) associated with reduced endocochlear and electrochemical potentials can also be modelled.

The computations show how Cx26 mutations could have a significant effect on the potentials developed across the basolateral membrane of OHCs. The computed reduction was largest for the $\mathrm{Cx} 26$ mutations such as $\mathrm{R} 75 \mathrm{~W}$ and $35 \mathrm{delG}$ where the potentials $\Delta \mathrm{E}_{\mathrm{OHC} \text {,max }}$ can be decreased by up to $35 \mathrm{~dB}$ at $30 \mathrm{kHz}$ relative to wild-type. As such potentials are thought to be the driver of the $\mathrm{OHC}$ somatic electromotility, we suggest that these types of mutation could result in hearing loss due to reduced $\mathrm{OHC}$ electromotility in addition to any hair cell loss resulting from failed ionic homeostasis in the organ of Corti. Accordingly, in the R75W animal model of Cx26-related deafness, there is an absence of oto-acoustic emissions despite OHCs apparently being unaffected (Minekawa et al. 2009). A reduced input for OHC electromotility could also explain the deafness phenotype of $35 \mathrm{delG}$ or $167 \mathrm{delT}$ human carriers, who also lack DPOAEs in the absence of any other audiological defects (Engel-Yeger et al. 2002; Morell et al. 1998).

\section{ACKNOWLEDGEMENT}

This research project was supported by European Commission FP6 Integrated Project EUROHEAR, LSHG-CT-20054-512063.

\section{REFERENCES}

Beltramello M, Piazza V, Bukauskas FF, Pozzan T, Mammano F (2005) ImPAIRED PERMEABILITy TO $\operatorname{Ins}(1,4,5) \mathrm{P} 3$ in a mutant connexin underlies recessive hereditary deafness. Nat Cell Biol 7:63-69

Bicego M, Beltramello M, Melchionda S, Carella M, Piazza V, Zelante L, Bukauskas FF, Arslan E, Cama E, Pantano S, Bruzzone R, D'Andrea P, Mammano F (2006) Pathogenetic role of the deafness-related M34T mutation of Cx26. Hum Mol Genet 15:2569-2587

Boettger T, Hubner CA, Maier H, Rust MB, Beck FX, Jentsch TJ (2002) Deafness and renal tubular acidosis in mice lacking the $\mathrm{K}-\mathrm{Cl}$ co-transporter Kcc4. Nature 416:874-878

Bruzzone R, Veronesi V, Gomes D, Bicego M, Duval N, Marlin S, Petit C, D'Andrea P, White TW (2003) Loss-of-function and residual channel activity of connexin 26 mutations associated with non-syndromic deafness. FEBS Lett 533:79-88

Cheatham MA, Low-Zeddies S, Naik K, Edge R, Zheng J, Anderson CT, DAllos P (2009) A chimera analysis of prestin knock-out mice. J Neurosci 29:12000-12008

Cheng X, Li L, Brashears S, Morlet T, Ng SS, Berlin C, Hood L, KeAts B (2005) Connexin 26 variants and auditory neuropathy/dyssynchrony among children in schools for the deaf. Am J Med Genet A 139:13-18

Cody AR, Russell IJ (1987) The response of hair cells in the basal turn of the guinea-pig cochlea to tones. J Physiol 383:551-569

Cohen-Salmon M, Ott T, Michel V, Hardelin JP, Perfettini I, Eybalin M, Wu T, Marcus DC, Wangemann P, Willecke K, Petit C (2002) Targeted ablation of connexin26 in the inner ear epithelial gap junction network causes hearing impairment and cell death. Curr Biol 12:1106-1111

DAllos P (1984) Some electrical circuit properties of the organ of Corti. II. Analysis including reactive elements. Hear Res 14:281-291

Dallos P, Cheatham MA (1976) Production of cochlear potentials by inner and outer hair cells. J Acoust Soc Am 60:510-512

Dallos P, SANTOS-SACChi J, Flock A (1982) Intracellular recordings from cochlear outer hair cells. Science 218:582-584 
Engel-Yeger B, Zaaroura S, Zlotogora J, Shalev S, Hujeirat Y, Carrasquillo M, Barges S, Pratt H (2002) The effects of a connexin 26 mutation-35delG - on oto-acoustic emissions and brainstem evoked potentials: homozygotes and carriers. Hear Res 163:93-100

Engel-Yeger B, Zaaroura S, Zlotogora J, Shalev S, Hujeirat Y, Carrasquillo M, Saleh B, Pratt H (2003) Otoacoustic emissions and brainstem evoked potentials in compound carriers of connexin 26 mutations. Hear Res 175:140-151

Fridberger A, de Monvel JB, Zheng J, Hu N, Zou Y, Ren T, Nuttall A (2004) Organ of Corti potentials and the motion of the basilar membrane. J Neurosci 24:10057-10063

Housley GD, Ashmore JF (1992) Ionic currents of outer hair cells isolated from the guinea-pig cochlea. J Physiol 448:73-98

JAGGER DJ, Forge A (2006) Compartmentalized and signal-selective gap junctional coupling in the hearing cochlea. J Neurosci 26:1260-1268

Johnstone BM, Patuzzi R, Syka J, Sykova E (1989) Stimulus-related potassium changes in the organ of Corti of guinea-pig. J Physiol 408:77-92

Kikuchi T, Adams JC, Miyabe Y, So E, Kobayashi T (2000) Potassium ion recycling pathway via gap junction systems in the mammalian cochlea and its interruption in hereditary nonsyndromic deafness. Med Electron Microsc 33:51-56

Kudo T, Kure S, IKeda K, Xia AP, Katori Y, Suzuki M, Kojima K, Ichinohe A, Suzuki Y, Aoki Y, Kobayashi T, Matsubara Y (2003) Transgenic expression of a dominant-negative connexin26 causes degeneration of the organ of Corti and non-syndromic deafness. Hum Mol Genet 12:995-1004

Lagostena L, Cicuttin A, Inda J, Kachar B, Mammano F (2001) Frequency dependence of electrical coupling in Deiters' cells of the guinea pig cochlea. Cell Commun Adhes 8:393-399

Liberman MC, Gao J, He DZ, Wu X, Jia S, Zuo J (2002) Prestin is required for electromotility of the outer hair cell and for the cochlear amplifier. Nature 419:300-304

Lopez-Poveda EA, Eustaquio-Martin A (2006) A biophysical model of the inner hair cell: the contribution of potassium currents to peripheral auditory compression. J Assoc Res Otolaryngol 7:218-235

Mammano F, Ashmore JF (1996) Differential expression of outer hair cell potassium currents in the isolated cochlea of the guinea-pig. J Physiol 496(Pt 3):639-646

Mammano F, Nobili R (1993) Biophysics of the cochlea: linear approximation. J Acoust Soc Am 93:3320-3332

Medica I, Rudolf G, Prpic I, Stanojevic M, Peterlin B (2005) Incidence of the del35G/GJB2 mutation in Croatian newborns with hearing impairment. Med Sci Monit 11:CR533-CR535

Minekawa A, Abe T, Inoshita A, Iizuka T, Kakehata S, Narui Y, Koike T, Kamiya K, Okamura HO, Shinkawa H, Ikeda K (2009) Cochlear outer hair cells in a dominant-negative connexin 26 mutant mouse preserve non-linear capacitance in spite of impaired distortion product otoacoustic emission. Neuroscience 164:1312-1319

Misrahy GA, Hildreth KM, Shinabarger EW, Gannon WJ (1958) Electrical properties of wall of endolymphatic space of the cochlea (guinea pig). Am J Physiol 194:396-402

Mistrik P, Ashmore J (2009) Using a large scale computational model to study the effect of longitudinal and radial electrical coupling in the cochlea. Concepts and challenges in the biophysics of hearing. In: Cooper NP, Kemp DT (eds) World scientic., pp 377-384

Mistrik P, Mullaley C, Mammano F, Ashmore J (2009) Three-dimensional current flow in a large-scale model of the cochlea and the mechanism of amplification of sound. J R Soc Interface 6:279-291

Morell RJ, Kim HJ, Hood LJ, Goforth L, Friderici K, Fisher R, Van Camp G, Berlin Ci, Oddoux C, Ostrer H, Keats B, Friedman tB (1998) Mutations in the connexin 26 gene (GJB2) among Ashkenazi Jews with nonsyndromic recessive deafness. N Engl J Med 339:1500-1505

Mountain DC, Cody AR (1999) Multiple modes of inner hair cell stimulation. Hear Res 132:1-14
Nickel R, Forge A (2008) Gap junctions and connexins in the inner ear: their roles in homeostasis and deafness. Curr Opin Otolaryngol Head Neck Surg 16:452-457

Nin F, Hibino H, Doi K, Suzuki T, Hisa Y, Kurachi Y (2008) The endocochlear potential depends on two $\mathrm{K}^{+}$diffusion potentials and an electrical barrier in the stria vascularis of the inner ear. Proc Natl Acad Sci USA 105:1751-1756

O'Beirne GA, PatuzZi RB (2007) Mathematical model of outer hair cell regulation including ion transport and cell motility. Hear Res 234:29-51

Ospeck M, Dong X-x, Iwasa KH (2003) Limiting frequency of the cochlear amplifier based on electromotility of outer hair cells. Biophys J 84:739-749

PeтIT C (2006) From deafness genes to hearing mechanisms: harmony and counterpoint. Trends Mol Med 12:57-64

Preyer S, Renz S, Hemmert W, Zenner HP, Gummer AW (1996) RECEPTOR POTENTIAL OF OUTER HAIR CELLS ISOLATED FROM BASE TO APEX OF THE ADULT GUINEA-PIG COCHLEA: IMPLICATIONS FOR COCHLEAR TUNING MECHANISM. Auditory NEURosCience 2:145-157

QuRaishi IH, Raphael RM (2008) Generation of the endocochlear potential: a biophysical model. Biophys J 94(8):L64-66

Rabionet R, Gasparini P, Estivill X (2000) Molecular genetics of hearing impairment due to mutations in gap junction genes encoding beta connexins. Hum Mutat 16:190-202

Ramamoorthy S, Deo NV, Grosh K (2007) A mechano-electroacoustical model for the cochlea: response to acoustic stimuli. J Acoust Soc Am 121:2758-2773

Raybould NP, JAGGer DJ, Housley GD (2001) Positional analysis of guinea pig inner hair cell membrane conductances: implications for regulation of the membrane filter. J Assoc Res Otolaryngol 2:362-376

Ruggero MA, Rich NC (1991) Furosemide alters organ of corti mechanics: evidence for feedback of outer hair cells upon the basilar membrane. J Neurosci 11:1057-1067

Russell IJ, SelLick PM (1978) Intracellular studies of hair cells in the mammalian cochlea. J Physiol 284:261-290

Santarelli R, Cama E, Scimemi P, Dal Monte E, Genovese E, Arslan E (2008) Audiological and electrocochleography findings in hearingimpaired children with connexin 26 mutations and otoacoustic emissions. Eur Arch Otorhinolaryngol 265:43-51

SANTOS-SACCHI J (1985) The effects of cytoplasmic acidification upon electrical coupling in the organ of Corti. Hear Res 19:207-215

SANTOS-SACCHI J (1991) Isolated supporting cells from the organ of Corti: some whole cell electrical characteristics and estimates of gap junctional conductance. Hear Res 52:89-98

Santos-Sacchi J, Dallos P (1983) Intercellular communication in the supporting cells of the organ of Corti. Hear Res 9:317-326

Spector AA, Brownell WE, Popel AS (2003) Effect of outer hair cell piezoelectricity on high-frequency receptor potentials. J Acoust Soc Am 113:453-461

StreliofF D (1973) A computer simulation of the generation and distribution of cochlear potentials. J Acoust Soc Am 54:620-629

Suesserman MF, Spelman FA (1993) Lumped-parameter model for in vivo cochlear stimulation. IEEE Trans Biomed Eng 40:237-245

Tasaki I (1957) Hearing. Annu Rev Physiol 19:417-438

Teubner B, Michel V, Pesch J, Lautermann J, Cohen-Salmon M, Sohl G, Jahnke K, Winterhager E, Herberhold C, Hardelin JP, Petit C, WiLLECKE K (2003) Connexin30 (Gjb6)-deficiency causes severe hearing impairment and lack of endocochlear potential. Hum Mol Genet 12:13-21

Winter H, Braig C, Zimmermann U, Engel J, Rohbock K, Knipper M (2007) THYROID HORMONE RECEPTOR ALPHA1 IS A CRITICAL REGULATOR FOR THE EXPRESSION OF ION CHANNELS DURING FINAL DIFFERENTIATION OF outer hair cells. Histochem Cell Biol 128:65-75

Yu N, Zhu ML, Zhao HB (2006) Prestin is expressed on the whole outer hair Cell basolateral surface. Brain Res 1095:51-58

Zhao HB, Kikuchi T, Ngezahayo A, White TW (2006) Gap junctions and Cochlear homeostasis. J Membr Biol 209:177-186 